\title{
KARAKTERISTIK VITAMIN C, VISKOSITAS DAN NILAI pH MINUMAN FUNGSIONAL KOMBINASI SARI BUAH NANAS (Ananas comosus) DAN JAHE (Zingiber officinale Roscoe.)
}

(Characteristics of vitamin $c$ and total solution solved for functional drink combination of pineapple and ginger fruit)

\section{Astuti $^{1}$ dan Satria Wati Pade ${ }^{2 *}$}

${ }^{1,2}$ Politeknik Gorontalo, Program Studi Teknologi Hasil Pertanian Jl. Muchlis Rahim, Desa Panggulo Barat, Kecamatan Botupingge, Kabupaten Bone Bolango, Provinsi Gorontalo, Kode Pos 96583

*Email: indonk@poligon.ac.id

\begin{abstract}
ABSTRAK
Tujuan penelitian ini adalah mengetahui kandungan vitamin $\mathrm{C}$, viskositas dan nilai $\mathrm{pH}$ pada minuman fungsional dengan kombinasi sari buah nanas dan jahe. Uji yang dilakukan adalah pengujian vitamin $\mathrm{C}$, viskositas dengan menggunakan Brookfield viscometer dan nilai $\mathrm{pH}$. Penelitian ini menggunakan beberapa perlakuan tingkat perbandingan sari buah nanas dan sari jahe yaitu perlakuan $\mathrm{A}=$ Sari nanas $80 \%$ : sari jahe $20 \%, \mathrm{~B}=$ sari nanas $50 \%$ : sari jahe $50 \%$ dan $\mathrm{C}=$ sari nanas $20 \%$ : sari jahe $80 \%$. Hasil penelitian menunjukkan bahwa perlakuan terbaik adalah perlakuan A dengan kombinasi sari nanas $80 \%$ : sari jahe $20 \%$ dibandingkan perlakuan $\mathrm{B}=$ sari nanas $50 \%$ : sari jahe $50 \%$ dan $\mathrm{C}=$ sari nanas $20 \%$ : sari jahe $80 \%$ dengan kandungan vitamin C 12,98mg/mL, viskositas $183,53 \mathrm{cP}$ dan nilai $\mathrm{pH} 4,86$.
\end{abstract}

Kata Kunci: Sari nanas; sari jahe; minuman fungsional; vitamin C

\begin{abstract}
The aim of this research was to know the content of vitamin $\mathrm{C}$, total dissolved solids and $\mathrm{pH}$ value in functional drinks with a combination of pineapple juice and ginger. The test carried out was testing vitamin $\mathrm{C}$, viscosity using Brookfield viscometer and $\mathrm{pH}$ value. This research used some treatments levels of comparison of pineapple juice and ginger juice, namely treatment $\mathrm{A}=$ pineapple juice $80 \%$ : ginger juice $20 \%, \mathrm{~B}=$ pineapple juice $50 \%$ : ginger juice $50 \%$ and $\mathrm{C}=$ pineapple juice $20 \%$ : ginger juice $80 \%$. The results showed that the best treatment was treatment $\mathrm{A}$ in combination with pineapple juice $80 \%$ : ginger juice $20 \%$ compared to treatment $\mathrm{B}=$ pineapple juice $50 \%$ : ginger juice $50 \%$ and $\mathrm{C}=$ pineapple juice 20\%: ginger juice $80 \%$ with vitamin C content $12.98 \mathrm{mg} / \mathrm{mL}$, viscosity $183.53 \mathrm{cP}$ and $\mathrm{pH}$ value 4,86 .
\end{abstract}

Keywords: Pineapple juice; ginger juice; functional drinks; vitamin C

\section{PENDAHULUAN}

Konsep pangan fungsional lahir sciring dengan makin mcningkatnya kesadaran masyarakat akan pentingnya hidup schat, dimana tuntutan konsumen serta pcnampakan dan cita rasa yang menarik, tetapi juga harus memiliki fungsi iisiologis tertentu bagi tubuh (Wijaya dan Manny., 2002)

Tubuh kita tcrdapat senyawasenyawa yang disebut antioksidan yaitu 
senyawa yang dapat menetralkan zat radikal bebas, sepcrti : Enzim SOD (Superoksida dismutasc), gluthatione dan katalase. Antioksidan juga dapat dipcrolch dari asupan makanan yang banyak mengandung vitamin $\mathrm{C}$, vitamin $\mathrm{E}$ dan betakaroten scrla senyawa fcnolik. Bahan makanan yang bisa menjadi sumber antioksidan adalah scpcrti, sayur-sayuran, buah-buahan seperti buah nanas, rempahrempah seperti jahe (Hanani, 2006).

Jahe merupakan salah satu komoditas tanaman obat yang memiliki banyak manfaat. Kandungan gingerol dan shogaol pada jahe memiliki peran sebagai antioksidan. Nilai dari tanaman tcrlctak pada rimpangnya yang umum dikonsumsi sebagai minuman penghangat, bumbu dapur dan penambah rasa dan sebagai bahan baku obat tradisional atau yang lebih populcr dengan istilah jamu (Bartley dan Jacobs, 2000). Tradisi mengkonsumsi tanaman obat atau rempah-rempah dalam bentuk ramuan jamu tradisional telah dikenal dan diakui secara luas oleh masyarakat. Namun sayangnya tidak semua masyarakat menyukai ramuan jamu tradisional karena citarasa jamu yang di identikkan dengan aroma tajam dan rasa pahit sehingga menurunkan nilai palatabilitas minuman tersebut. Akibatnya, tidak semua masyarakat mendapatkan khasiat kesehatan dari ramuan jamu tradisional, Sehingga untuk meningkatkan daya terima masyarakat terhadap tanaman jahe perlu dilakukan adanya kombinasi jahe dengan buah nanas.

Buah nanas memiliki rasa manis sampai agak masam segar. Nanas juga memiliki khasiat yang baik bagi kesehatan antara lain mempunyai efek antiinflamasi, antioksidan, antibakteri, dan antifungi yang terkandung dari saponin, flavonoid, fan polifenol (Daniswara, 2008). Buah nanas yang digunakan untuk dikonsumsi adalah buah nanas yang sudah masak, ditandai dengan perubahan mata kulit buah nanas dari wama hijau menjadi wama hijau kekuningan, tangkai buah mengkerut dan mahkota buah terbuka. Salah satu altematif yang dapat dilakukan unluk mengantisipasi hasil panen yang melimpah dan sebagai diversifikasi pangan adalah menjadi minuman segar atau sari buah nanas.

Faktor utama yang menentukan penerimaan konsumen adalah sifat sensori, kliususnya aspek citarasa dan wama sualu bahan bahan pangan. Oleh karena itu, nilai kesukaan menjadi faktor penting dalam formulasi minuman fungsional selain aspek nutrisi dan fisiological yang mampu memberi pengaruh kesehatan terhadap tubuh. Dengan penambahan bahan pangan yang berfungsi sebagai sifat dasar makanan atau minuman dapat meningkatkan penerimaan konsumen.

METODE PENELITIAN 
Alat : Blender, pisau, talenan, loyang, pisau, corong, timbangan, wadah plastik, panci, kompor, viskometer, kcrtas saring dan alat analisa lainnya.

Bahan : Buah nanas varietas Queen, jahe merah, gula pasir, asam sitrat, air, aquades dan bahan kimia untu analisa.

\section{Metodologi Penelitian}

Penelitian ini menggunakan metode rancangan acak lengkap (RAL) dengan tiga perlakuan kombinasi sari buah nanas dan sari jahe yaitu :

$A=$ Sari nanas $80 \%$ : sari jahe $20 \%$

$\mathrm{B}=$ Sari nanas $50 \%$ : sari jahe $50 \%$

$\mathrm{C}=$ Sari nanas 20\%: sari jahe $80 \%$

Masing-masing perlakuan diulang sebanyak tiga kali. Penelitian ini terbagi atas tiga tahap yaitu pembuatan sari nanas, sari jahe dan minuman fungsional.

\section{Prosedur Pembuatan}

\section{Prosedur Pembuatan Sari Buah Nanas}

Pembuatan sari buah nanas diawali dengan sortasi, pengupasan dan pembersihan buah nanas yang dilanjutkan dengan pemotongan dengan ukuran kecil. Nanas yang telah dipotong selanjutnya ditimbang sebanyak $100 \mathrm{~g}$ dan dimasukkan kedalam blender untuk dihaluskan sampai didapatkan bubur buah nanas. Bubur nanas ditambahkan air sebanyak $1000 \mathrm{~mL}$ dan dipanaskan selama 30 menit. Bubur nanas yang telah dipanaskan disaring dan dibuang ampasnya.

\section{Prosedur Pembuatan Sari Jahe}

Proses pembuatan sari jahe diawali dengan sortasi dan pengupasan kulitnya. Jahe ditimbang sebanyak 100g kemudian dikeprek dan direbus dalam air $1000 \mathrm{~mL}$ selama 30 menit. Air rebusan jahe disaring hingga didapat sari jahe.

\section{Prosedur Pembuatan Minuman Fungsional}

Pembuatan minuman fungsional dilakukan dengan mencampurkan sari buah nanas dan sari jahe sesuai perlakuan. Setelah tercampur, ditambahkan gula pasir sebanyak $10 \%$ dan asam sitrat $0,02 \%$ kemudian disaring hingga didapatkan minuman fungsional.

Proses pembuatan minuman fungsional sari buah nanas dan sari jahe dapat dilihat pada gambar berikut.

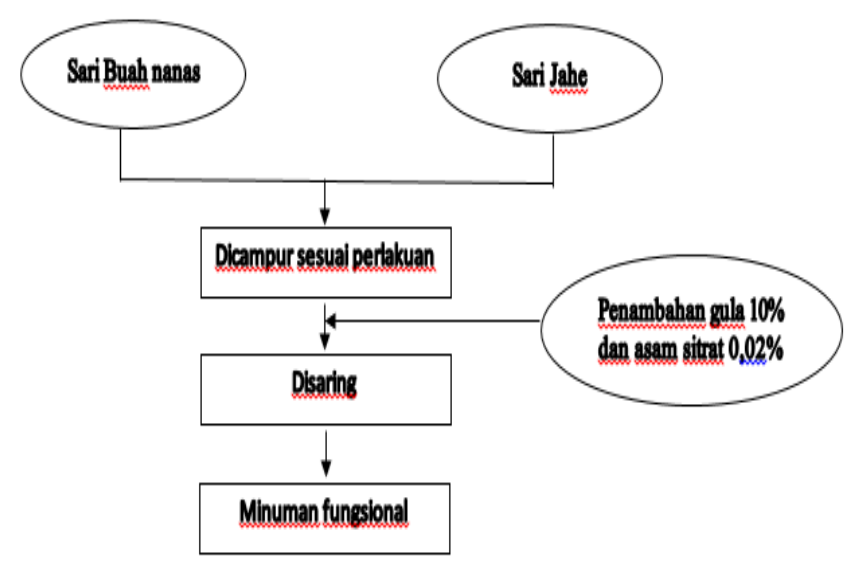

Gambar 1. Proses pembuatan minuman fungsional 
kandungan vitamin $\mathrm{C}$ nya.

\section{HASIL DAN PEMBAHASAN}

\section{Vitamin C}

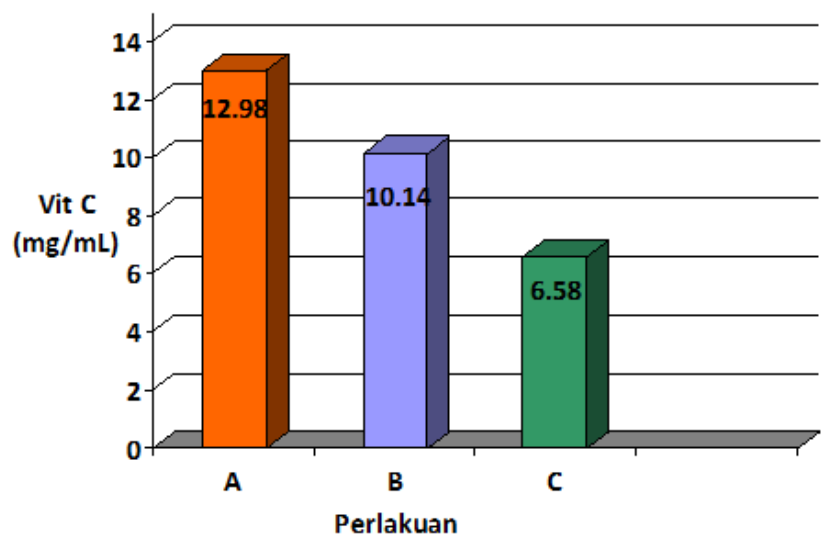

Gambar 2. Kandungan Vitamin C minuman fungsional sari buah nanas dan sari jahe

Dari hasil analisa kandungan vitamin $\mathrm{C}$ pada masing- masing perlakuan, diketahui bahwa perlakuan A (Nenas 80\% : Jahe 20\%), memiliki kandungan vitamin $\mathrm{C}$ sebesar 12,98 $\mathrm{mg} / \mathrm{mL}$, perlakuan B (Nenas 50\% : Jahe $50 \%$ ) sebesar 10,14 $\mathrm{mg} / \mathrm{mL}$ dan perlakuan C (Nenas 20\% : Jahe 80\%) seb3sar $6,58 \mathrm{mg} / \mathrm{mL}$. Dari hasil tersebut terlihat bahwa perlakuan A memiliki kandungan vitamin $\mathrm{C}$ lebih tinggi dibanding perlakuan $\mathrm{B}$ dan perlakuan $\mathrm{C}$. Hal ini di karenakan jumlah sari nanas lebih banyak ditambahkan pada perlakuan A dibandingkan dengan perlakuan lainnya. Semakin tinggi komposisi sari nanas semakin tinggi pula

\section{Viskositas}

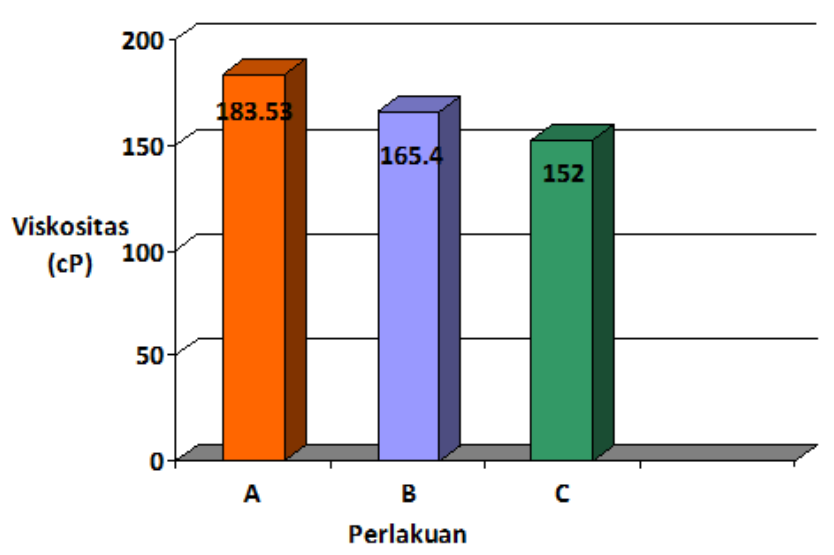

Gambar 3. Viskositas minuman fungsional sari buah nanas dan sari jahe

Pada gambar terlihat bahwa viskositas perlakuan A ( Nenas $80 \%$ : Jahe $20 \%$ ) yaitu $183,53 \mathrm{cP}$, viskositas perlakuan B (Nenas 50\% : Jahe 50\%) sebesar 165,40 cP dan viskositas perlakuan C (Nenas 20\% : Jahe 80\%) sebesar 152 cP. Nilai viskositas tertinggi terdapat pada perlakuan A sedangkan terendah yaitu perlakuan C. Pembentukan viskositas juga dipengaruhi oleh penambahan gula pada semua perlakuan. Jumlah gula yang ditambahkan sama untuk setiap perlakuan. Perbedaan nilai viskositas dikarenakan perbedaan komposisi sari buah nanas dan jahe di tiap perlakuan.

Viskositas pada perlakuan A ini tinggi diduga karcna adanya 
penambahnn gula dan kandungan gula yang ada pada buah nanas. Hal ini disebabkan karena gula mempunyai sifat hidrofilik yang disebabkan oleh adanya gugus hidroksil dalam struktur molekulnya. Gugus hidroksil tersebut akan berikatan dengan molekul air melalui ikatan hidrogen, akibat keadaan tersebut air yang terdapat di dalam bahan pangan akan berkurang (Eveline, 2010).

Menurut Winarno (2008), peningkatan viskositas dipengaruhi dengan adanya penambahan gula. Konsentrasi gula yang tinggi mengandung derajat brix yang tinggi sehingga meningkatkan viskositas disebabkan adanya padatan yang dapat mengikat air, sukrosa, dan asarn sitrat sehingga semakin banyak ikatan doublehelix yang terbentuk dan menangkap air untuk membentuk gel.

\section{Nilai pH}

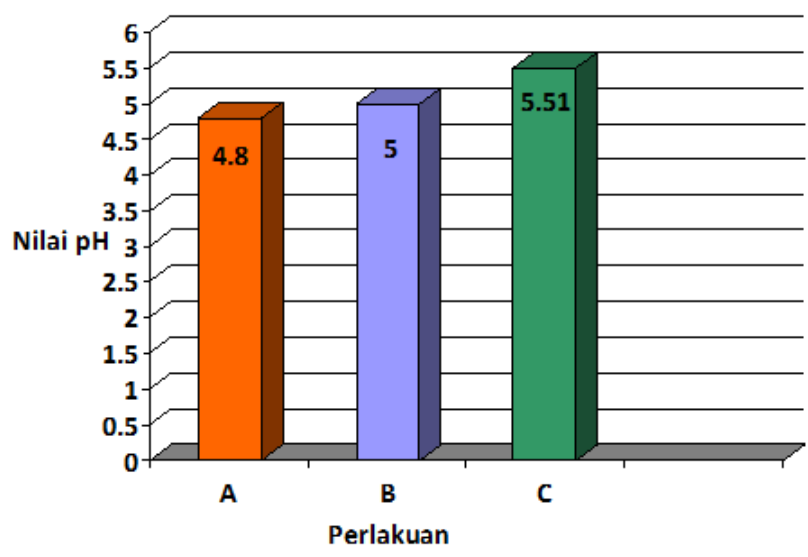

Gambar 4. pH minuman Fungsional sari buah nanas dan sari jahe

Berdasarkan Gambar diatas, hasil pengujian $\mathrm{pH}$ terhadap minuman fiingsional dengan kombinasi sari buah nanas dan jahe menujukkan nilai ratarata semua perlakuan yakni A sebesar 4,8, B sebesar 5,0 dan C sebesar 5,51. Nilai rata-rata semua perlakuan yang tertinggi $\mathrm{pH}$ yaitu terdapat pada $\mathrm{C}$, sedangkan yang terendah derajat keasamanya $(\mathrm{pH})$ yaitu pelakuan $\mathrm{A}$. Nilai pH pada masing- masing perlakuan tersebut berada pada kisaran $\mathrm{pH} 4-5$. Perbedaan $\mathrm{pH}$ tersebut dikarcnakan perbedaan komposisi sari buah nanas dan jahe pada setiap perlakuan. Rendahnya nilai $\mathrm{pH}$ pada perlakuan A ini diduga karena dipengaruhi oleh kandungan asam-asam organik yang ada pada sari nenas. Darma $d k k$ (2013) mcnyatakun bahwa asam-asam yang terkandung dalam buah nanas adalah asam sitrat, asam malat dan asam oksalat. Nilai pH ini berhubungan dengan nilai vitamin $\mathrm{C}$ semakin rendah nilai $\mathrm{pH}$, semakin asam pula suatu bahan. Jadi, hubungan antara vitamin $\mathrm{C}$ dan keasaman bukan sekadar keidentikan dengan rasanya, melainkan juga sifat kimiawinya. Oleh karena itu, nilai vitamin $\mathrm{C}$ yang tinggi dari minuman fiingsional diduga menjadi 
salah salu penyebab nilai $\mathrm{pH}$ pada minuman rendah. Hubungan antara nilai $\mathrm{pH}$ dan vitamin $\mathrm{C}$ yaitu berbanding terbalik, semakin rendah nilai $\mathrm{pH}$ semakin tinggi kandungan vitamin $\mathrm{C}$. Menurut Farikha $d k k$ (2013), stabilitas asam askorbat akan meningkat dengan menurunnya nilai $\mathrm{pH}$.

\section{KESIMPULAN}

Formulasi terbaik terdapat pada perlakuan A dengan kombinasi sari buah nanas $80 \%$ dan Jahe 20\% dengan kandungan vitamin C $(12.98 \mathrm{mg} / \mathrm{mL})$. viskositas $183.53 \mathrm{cP}$ dan nilai $\mathrm{pH} 4,8$.

\section{DAFTAR PUSTAKA}

Bartle, J dan E. Jacobs, 2000. Effect Of Drying On Flavor Compounds In Australian Ground Ginger (Zingiber officinale rose). Journal Of The Science Of Food and Agriculture 80 : 209-2015.

Darma, G.S.,D, Puspitasari dan E, Noerhartati. 2013. Pembuatan Es Krim Jagung Manis Kajian Jenis Zat Penstabil, Konsentrasi Non Dairy Es Krim serta Aspek Kelayakan Finansial. Jurnal Reka Agroindustry. 1 (1) : 25-46

Eveline, S. 2010. Pengaruh Konsentrasi Kappa Karagenan Terhadap Karakteristik Minuman Serbuk Jelly Belimbing Manis. Jurnal Ilmu Dan Teknologi Pangan. 8 (1) : $31-44$.
Farikha, I,N.,Choirul Anam dan E. Widowati. 2013. Pengaruh Jenis Dan Bahan Penstabil Terhadap Karakteristik Fisikokimia Sari Buah Naga Merah (Hylocereus polyrhizus). Jurnal Tekno Sains Pangan. 2 (1).

Hanani, R. 2006. Tanaman Berkhasiat Antioksidan. Penebar Swadaya. Jakarta.

Wijaya dan Manny., 2002. Pangan Fungsional dan Kontribusinya Bagi Kesehatan. Charisma.,Women And Education. Jakarta.

Winarno, F.G . 2008. Kimia Pangan dan Gizi. Gramedia Pustaka Utama. Jakarta. 